\title{
PERENCANAAN JADWAL PATROLI KEAMANAN LAUT BERDASARKAN POLA SEBARAN KLOROFIL-A DAN HASIL TANGKAPAN SKIPJACK TUNA DI PERAIRAN LAUT MALUKU
}

\author{
Dhedy Anggriawan Maydwika', Widodo Setyo Pranowo ${ }^{2,4}$, Gentio Harsono ${ }^{3}$, Nawanto Budi \\ Sukoco ${ }^{4}$, Iska Putra ${ }^{4}$ \\ ${ }^{1}$ Mahasiswa Program Studi Hidrografi, STTAL \\ ${ }^{2}$ Peneliti pada Pusat Riset Kelautan, Badan Riset dan SDM, KKP \\ ${ }^{3}$ Peneliti pada Pusat Hidrografi dan Oseanografi, TNI AL \\ ${ }^{4}$ Dosen pada Program Studi Hidrografi, STTAL \\ Penulis : dhedy56cadet@gmail.com
}

\begin{abstract}
ABSTRAK
Perairan Laut Maluku memiliki hubungan kuat dengan Samudera Pasifik yang mengakibatkan maraknya kegiatan IIlegal Unregulated and Unreported Fishing (IUU-Fishing). Patroli keamanan laut dalam rangka mengatasi IUU-Fishing saat ini masih mengandalkan informasi dari nelayan setempat yang diterima oleh pangkalan TNI AL terdekat, metode ini tentunya kurang efektif dan efisien. Penelitian ini menggunakan data sekunder akuisisi satelit klorofil-a level 3 dengan analisis korelasi pergeseran waktu yang digunakan untuk menentukan tingkat kesesuaian hubungan antara hasil tangkapan skipjack tuna dan konsentrasi klorofil-a, hal ini diperlukan untuk menganalisis hasil tangkapan tuna, termasuk hubungannya dengan klorofil-a secara spasial. Analisis terhadap data tersebut dapat mengidentifikasi dan menjadwalkan waktu terbaik untuk patroli keamanan laut. Hasil awal menunjukkan efektivitas operasi keamanan laut untuk simulasi selama lima tahun (Desember 2010 - November 2015). Hasil tangkapan skipjack tuna dipengaruhi oleh distribusi klorofil-a dengan koefisien korelasi sebesar $(-0,31)$ dengan jeda waktu satu bulan.
\end{abstract}

Kata kunci : IUU-Fishing, Klorofil-a, Skipjack Tuna, Laut Maluku.

\section{ABSTRACT}

The Molucca Sea is strongly connected with the Pacific Ocean which have led to the probability of Illegal Unregulated and Unreported Fishing (IUU-Fishing) activities. Marine security patrols in the context of overcoming IUU-Fishing currently is still rely on information from local fishermen received by the nearest Naval base, this method is certainly less effective and efficient. This research is using secondary data on level 3 chlorophyll-a satellite acquisitions. A time shifting correlation analysis has been employed in order to determine the level of fitness of the relationship between skipjack tuna catches with chlorophyll-a concentrations. It is necessary to conduct a research to analyses the catch of skipjack tuna, including its relationship with chlorophyll-a spatial distribution. Analysis of these data can identify and schedule the best time for marine security patrols. This preliminary result show promising effectiveness of marine security operations for five years simulation (December 2010 - November 2015). The skipjack tuna catch was influenced by the distribution of chlorophyll-a with the correlation coefficient $(-0,31)$ with a one-month time lag.

Keywords: IUU-Fishing, Chlorophyll-a, Skipjack Tuna, Molucca Sea. 


\section{PENDAHULUAN}

\section{Latar Belakang}

Laut Maluku merupakan wilayah potensial sumber daya perikanan tuna bernilai ekonomi yang menjadikannya sebagai komoditas utama dari subsektor perikanan, sehingga rawan terjadi IUU-Fishing (IIlegal Unreported and Unregulated Fishing) karena posisinya yang berbatasan dengan Samudera Pasifik. Hal ini disebabkan karena Samudera Pasifik merupakan pintu masuk bagi kapalkapal ikan dari negara tetangga, seperti Philipina, Thailand dan Taiwan. Kegiatan illegal fishing yang umum terjadi di perairan tersebut adalah penangkapan ikan tanpa izin, penangkapan ikan dengan menggunakan izin palsu, penangkapan ikan dengan menggunakan alat tangkap terlarang, penangkapan ikan pada daerah yang tidak sesuai dengan daerah yang diizinkan dan penangkapan ikan yang hasil tangkapannya tidak dilaporkan (Naim, 2010).

Upaya yang dilakukan dalam pencegahan dan pemberantasan IUU-Fishing menggunakan sistem patroli TNI Angkatan Laut yang saat ini masih mengandalkan informasi dari nelayan setempat dirasa masih kurang efektif. Menurut (Nikyuluw, 2005), analisis citra satelit (remote sensing) dapat diaplikasikan pada bidang perikanan dalam menentukan zona penangkapan ikan pada wilayah perairan tertentu, citra satelit akan menghasilkan informasi kondisi lingkungan laut yang dapat diamati, antara lain kandungan klorofil-a, suhu permukaan laut, kondisi cuaca dan pola arus permukaan. Dengan demikian citra satelit juga dapat digunakan untuk memperkirakan kapan suatu wilayah perairan terjadi blooming fitoplankton dan memperkirakan ketika jumlah tangkapan ikan meningkat, hal ini dapat membantu efektivitas patroli keamanan laut terhadap IUU-Fishing. Salah satu komoditi di Laut Maluku yang menjadi incaran adalah ikan skipjack tuna (FAO, 1983).

Adapun tujuan dari artikel ini adalah untuk mengetahui karakteristik sebaran klorofil-a di Perairan Laut Maluku, hubungan antara sebaran klorofil-a dan hasil tangkapan ikan skipjack tuna serta mengidentifikasi potensi tindak pidana IUU-Fishing berdasarkan sebaran klorofil-a dan hasil tangkapan skipjack tuna di Perairan Laut Maluku. Artikel ini diharapkan dapat memberikan pengetahuan untuk meningkatkan efektivitas operasi keamanan laut dan mencegah terjadinya IIlegal Unreported and Unregulated Fishing (IUUFishing).

\section{METODE PENELITIAN}

\section{Jenis Penelitian}

Penelitian ini menerapkan metode kuantitatif yang memenuhi kaidah ilmiah berupa angka-angka dan menganalisanya menggunakan statistik (Harsono, 2015), metode lain yang digunakan untuk menganalisis karakteristik hubungan antara sebaran klorofil-a dan jumlah tangkapan skipjack tuna adalah metode statistik time shifting correlation, yaitu suatu metode sederhana untuk melakukan investigasi hubungan fungsional di antara beberapa variabel (Sarwono, 2006). Penulis juga menggunakan metode perata-rataan secara spasial terhadap bulanan, musiman dan tahunan untuk melakukan analisis spasial dan temporal yang divisualisasikan menggunakan software Ocean Data View (Pranowo, 2015).

\section{Sumber Data}

Data klorofil-a yang digunakan pada penelitian ini adalah data sekunder level 3 citra satelit Aqua Modis yang diperoleh dari website NASA Ocean Color, sedangkan data perikanan tangkap skipjack tuna merupakan public domain data yang diunduh dari website WCPFC (Western and Central Pacific Fisheries Commission).

\section{Lokasi Penelitian}

Lokasi penelitian di perairan Laut Maluku dengan batas koordinat $0^{\circ}-5^{\circ} \mathrm{LU}$ dan $125^{\circ} \mathrm{BT}-130^{\circ} \mathrm{BT}$. (Gambar 1).

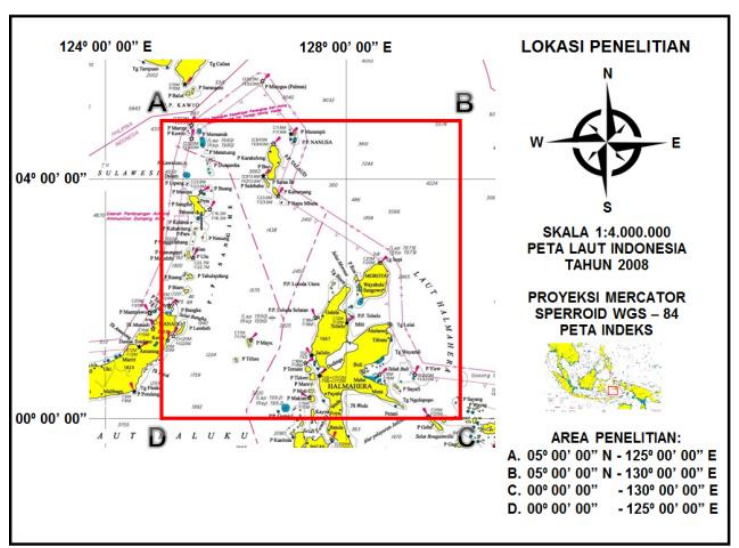

Gambar 1. Lokasi Penelitian

Sumber : (Peta nomor 3, Pushidrosal)

\section{Instrumen Pengumpulan Data}

Perangkat keras yang digunakan dalam penelitian ini adalah Komputer (laptop) dengan spesifikasi Microsoft Windows 8.1 Pro operating system, Processor AMD A10-5745M $A P U$ with Radeon ${ }^{\mathrm{TM}} \mathrm{HD}$ Graphics $2.10 \mathrm{GHz}$, installed memory (RAM) 8 GB, HDD 1000 $G B$. Perangkat lunak yang digunakan antara lain: Ocean Data View (ODV) 5.1.7, SPSS 16.0, MS.Excel 2010 dan MS.Word 2010. 
Teknik Pengolahan dan Analisis Data

Data klorofil-a yang telah melalui tahap kontrol, selanjutnya dilakukan proses gridding menggunakan software ODV, proses gridding bertujuan untuk menginterpolasi apabila terdapat data yang kosong atau kurang baik, sehingga diperoleh color plot distribusi spasial klorofil-a bulanan di Perairan Laut Maluku. Untuk mendapatkan nilai ratarata distribusi spasial klorofil-a per bulan, dilakukan export station data spreadsheet file (.txt) kemudian secara sederhana dapat dihitung dengan rumus rata-rata menggunakan microsoft excel :

$$
\bar{x}=\frac{x_{1}+x_{2}+x_{3}+\ldots+x_{n}}{n}
$$

dimana :

$$
\begin{array}{ll}
\bar{x} & =\text { Rata-rata }\left(\mathrm{mg} / \mathrm{m}^{3}\right) \\
x_{n} & =\text { Konsentrasi klorofil-a tiap stasiun } \\
& \quad\left(\mathrm{mg} / \mathrm{m}^{3}\right) \\
n & =\text { Banyaknya data }
\end{array}
$$

Untuk memudahkan analisis data secara visual, color plot yang berisi informasi mengenai pola sebaran klorofil-a secara spasial dan temporal tersebut selanjutnya dioverlay dengan base map daratan (.shp) dan disimpan dalam format $P N G$ images. Analisis sebaran klorofil-a menggunakan klasifikasi dari Gower (1972) pada Tabel 1.

Tabel 1. Klasifikasi Konsentrasi Klorofil-a

\begin{tabular}{|c|c|}
\hline Konsentrasi Klorofil-a dalam Mg/m & Penilaian \\
\hline $0.0 \mathrm{mg} / \mathrm{m}^{3}-<0.1 \mathrm{mg} / \mathrm{m}^{3}$ & Rendah \\
\hline $0.1 \mathrm{mg} / \mathrm{m}^{3}-0.2 \mathrm{mg} / \mathrm{m}^{3}$ & Sedang \\
\hline$>0.2 \mathrm{mg} / \mathrm{m}^{3}$ & Tinggi \\
\hline
\end{tabular}

(Sumber : Gower, 1972)

Pengolahan data tentang hasil dan upaya penangkapan ikan skipjack tuna menggunakan analisis Catch Per Unit Effort (CPUE) atau hasil tangkapan per upaya penangkapan. Penghitungan CPUE bertujuan untuk mengetahui kelimpahan ikan skipjack tuna berdasarkan total hasil tangkapan (catch) dan upaya penangkapan (effort). Rumus yang digunakan yaitu :

dimana :

$$
\text { CPUE }=\frac{\text { Catch }}{\text { Effort }}
$$

CPUE = Hasil tangkapan per upaya penangkapan (metric ton/days)

Catch = Total hasil tangkapan (metric ton)

Effort $=$ Total upaya penangkapan (days)
Hasil pengolahan data yang telah terkumpul selanjutnya dilakukan analisis bulanan/musiman secara spasial dan temporal, kedua analisis ini bertujuan untuk mengetahui karakteristik serta hubungan fungsional antar parameter, analisis lebih detail yang digunakan yaitu dengan metode statistik time shifting correlation yang bertujuan untuk mengetahui nilai koefisien korelasi yang menyatakan tingkat keeratan hubungan antar parameter, dimana signal $A=$ konsentrasi klorofil-a rata-rata, signal $B=$ skipjack tuna CPUE.

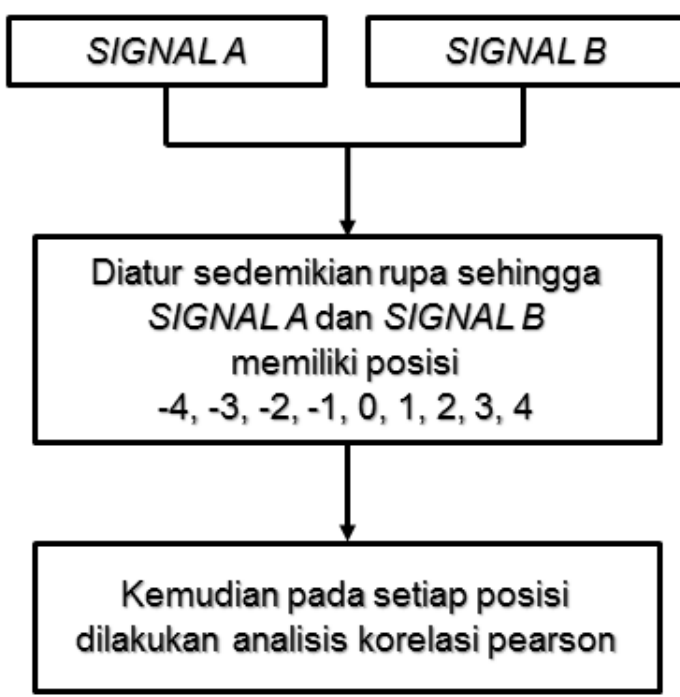

Gambar 2. Diagram Time Shifting Correlation Analysis

Persamaan korelasi pearson menurut (Chatfield, 1984) adalah sebagai berikut :

$$
r=\frac{\left[n \sum_{i=1}^{n} X i Y i-\left(\sum_{i=1}^{n} X i\right)\left(\sum_{i=1}^{n} Y i\right)\right]}{\sqrt{\left(n \sum_{i=1}^{n} X i^{2}-\left(\sum_{i=1}^{n} X i\right)^{2}\right)-\left(n \sum_{i=1}^{n} Y i^{2}-\left(\sum_{i=1}^{n} Y i\right)^{2}\right)}}
$$
dimana :

$r \quad=$ Koefisien korelasi

$\mathrm{Xi} \quad=$ Parameter $(\mathrm{X})$

$Y i \quad=$ Parameter $(\mathrm{Y})$

Koefisien korelasi menunjukkan kekuatan (strength) hubungan linier dan arah hubungan dua variabel acak. Jika koefisien korelasi positif, maka kedua variabel mempunyai hubungan searah. Artinya jika nilai variabel $X$ tinggi, maka nilai variabel $Y$ akan tinggi pula. Sebaliknya jika koefisien korelasi negatif, maka kedua variabel mempunyai hubungan terbalik. Artinya jika nilai variabel $X$ tinggi, maka nilai variabel $Y$ akan menjadi rendah dan berlaku sebaliknya (Sarwono, 2006). 


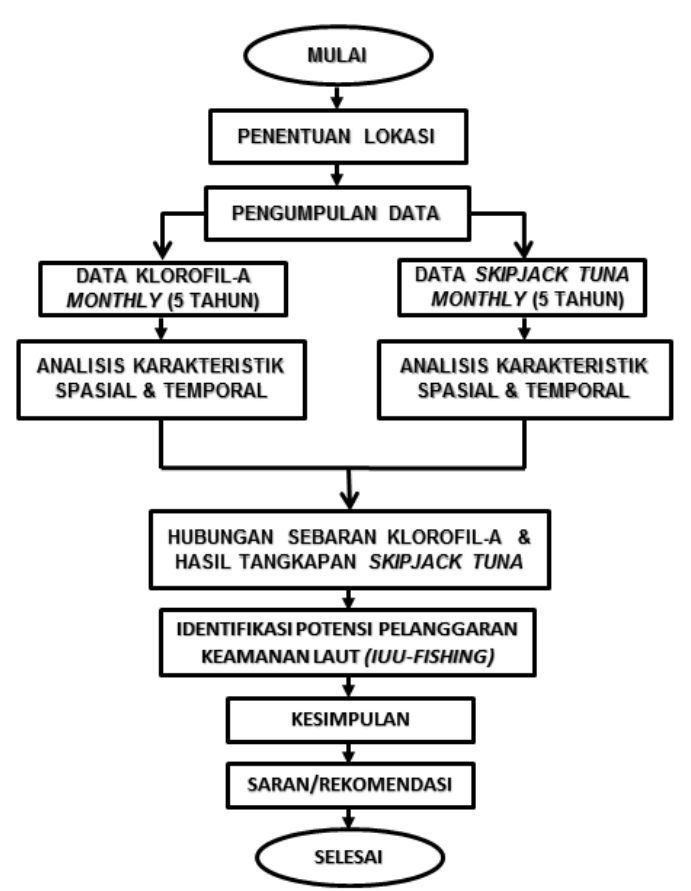

Gambar 3. Diagram Alir Penelitian

\section{HASIL DAN PEMBAHASAN}

\section{Karakteristik Konsentrasi Klorofil-a}

Analisis pada penelitian ini sesuai dengan riset yang dilakukan oleh (Syetiawan, 2015) yakni menentukan zona potensi penangkapan ikan berdasarkan pola sebaran klorofil-a. Klorofil-a merupakan pigmen yang digunakan dalam proses fotosintesis yang terdapat pada organisme fitoplankton dan merupakan sumber makanan bagi ikan di laut (Ramansyah, 2009). Klorofil-a mampu menyerap cahaya biru dan hijau, sehingga keberadaan fitoplankton dapat dideteksi berdasarkan kemampuan klorofil-a tersebut (Adnan, 2010). Klorofil-a termasuk salah satu parameter yang sangat menentukan produktivitas primer di laut. Sebaran dan tinggi rendahnya konsentrasi klorofil-a sangat terkait dengan kondisi oseanografis suatu perairan. Kandungan klorofil-a dapat digunakan sebagai ukuran banyaknya fitoplankton pada suatu perairan tertentu dan dapat digunakan sebagai petunjuk produktivitas perairan (Fausan, 2011). Ketika konsentrasi klorofil-a meningkat maka bisa menjadi indikator adanya potensi ikan.

Penelitian ini menampilkan color plot berupa degradasi warna dan kontur konsentrasi klorofil-a menggunakan acuan peak tiap-tiap musim pada bulan Januari yang mewakili musim barat, bulan April yang mewakili musim peralihan I, bulan Juli yang mewakili musim timur, serta bulan Oktober yang mewakili musim peralihan II. Distribusi klorofil-a di suatu perairan bervariasi berdasarkan letak geografis dan kedalaman perairan. Nilai klorofil-a dipengaruhi oleh intensitas cahaya matahari, selain itu kandungan nutrien dalam perairan juga mempengaruhi konsentrasi klorofil-a. Ratarata konsentrasi klorofil-a di perairan Laut Maluku periode Desember 2010 - November 2015 adalah $0,1126-0,3260 \mathrm{mg} / \mathrm{m}^{3}$. Hasil pengolahan data menunjukkan konsentrasi klorofil-a lebih tinggi pada perairan pantai dan pesisir, sedangkan nilai konsentrasi rendah berada di daerah lepas pantai.

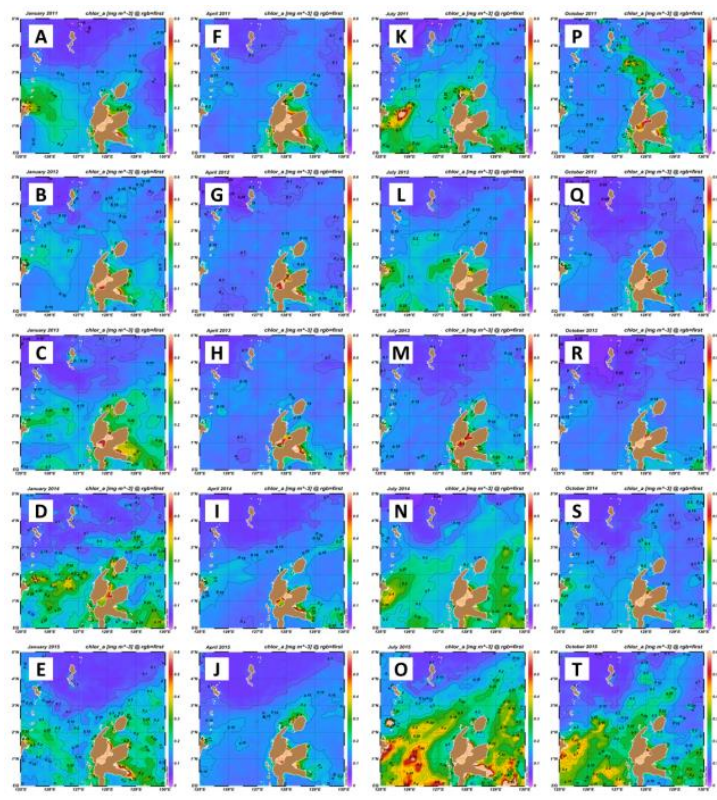

Gambar 4. Konsentrasi Klorofil-a Musim Barat (A) 2011, (B) 2012, (C) 2013, (D) 2014, (E) 2015; Musim Peralihan I (F) 2011, (G) 2012, (H) 2013, (I) 2014, (J) 2015; Musim Timur (K) 2011, (L) 2012, (M) 2013, (N) 2014, (O) 2015; Musim Peralihan II (P) 2011, (Q) 2012, (R) 2013, (S) 2014, (T) 2015.

Tingginya konsentrasi klorofil-a pada perairan pesisir disebabkan oleh adanya suplai nutrien dalam jumlah besar melalui runoff dari daratan yang berasal dari pembuangan limbah organik, hal ini sesuai dengan pernyataan Rasyid (2013), bahwa penyebab tingginya konsentrasi klorofil-a berasal dari suplai nutrien yang tinggi yang berasal dari buangan manusia (antropogenik) yang ditransfer melalui arus ke perairan, sedangkan sebaran klorofil-a memiliki konsentrasi lebih rendah pada perairan lepas pantai karena tidak adanya suplai nutrien dari daratan secara langsung. Pada gambar 4 menunjukkan adanya area tertentu di perairan lepas pantai yang memiliki konsentrasi klorofil-a dalam jumlah yang cukup tinggi seperti pada citra musim barat tahun 2013 - 2015, musim timur tahun 2011, 2014 dan 2015 serta pada musim peralihan II tahun 2011 dan 2015. Keadaan ini disebabkan oleh tingginya konsentrasi nutrien yang dihasilkan melalui proses fisik massa air, dimana massa air dalam mengangkat nutrien 
dari lapisan dalam ke lapisan permukaan (Valiela, 1984).

Percampuran massa air dapat terjadi secara vertikal maupun horizontal, percampuran massa air vertikal dipengaruhi oleh hembusan angin, sedangkan percampuran massa air horizontal yang dipengaruhi oleh Angin Muson dan Arlindo menyebabkan terjadinya percampuran antara dua massa air yang berbeda di suatu perairan, misalnya pada saat musim timur, massa air dari Samudera Pasifik akan bertemu dengan massa air di perairan Laut Banda yang mengalami upwelling atau ketika berhembus Angin Muson Tenggara sehingga terjadi penyebaran massa air dari Perairan Indonesia bagian timur menuju Perairan Indonesia bagian barat serta sebaliknya terjadi ketika berhembus Angin Muson Barat Laut. Dengan demikian sirkulasi dan percampuran massa air akan mempengaruhi produktivitas primer suatu perairan. Tingginya konsentrasi klorofil-a dominan yang terjadi pada saat Musim Timur dapat diakibatkan oleh wilayah perairan lain dari mana massa air tersebut berasal, serta hembusan Angin Muson Tenggara yang mengakibatkan sebagian besar Perairan Indonesia bagian Timur mengalami pengadukan.

Tabel 3. Tahun Kejadian ENSO dan IOD

\begin{tabular}{|c|c|c|c|}
\hline & IOD fase negatif & Netral & IOD fase positif \\
\hline El Nino Sangat Kuat & & & 198219972015 \\
\hline El Nino Kuat & & 1965 & 1972 \\
\hline El Nino Sedang & & 1986198720022009 & 19631991 \\
\hline El Nino Lemah & & $\begin{array}{l}1968196919761979 \\
2004\end{array}$ & 199420061977 \\
\hline Normal & $\begin{array}{l}1960198119891992 \\
199620132014\end{array}$ & $\begin{array}{l}1962196619781980 \\
1985199019932001 \\
200320052008\end{array}$ & 19612012 \\
\hline La Nina Lemah & 196419742016 & $\begin{array}{l}1970197119841995 \\
20002011\end{array}$ & 196719721983 \\
\hline La Nina Sedang & 19982010 & 19992007 & \\
\hline
\end{tabular}

(Sumber : www.ggweather.com (Meyers, Mclntosh, Pigot, \& Pook, 2007)

Konsentrasi klorofil-a tinggi dominan terjadi pada tahun 2015, secara spasial terlihat kenaikan nilai rata-rata konsentrasi sebesar 0,18 hingga $0,33 \mathrm{mg} / \mathrm{m}^{3}$ pada musim timur, yakni antara bulan Juni, Juli dan Agustus, kemudian berangsur menurun pada musim peralihan II, yaitu pada bulan September dengan nilai konsentrasi rata-rata antara 0,22 $\mathrm{mg} / \mathrm{m}^{3}$, bulan Oktober dengan konsentrasi rata-rata $0,19 \mathrm{mg} / \mathrm{m}^{3}$, serta bulan November dengan nilai konsentrasi rata-rata $0,15 \mathrm{mg} / \mathrm{m}^{3}$. Keadaan ini diduga dapat dipengaruhi oleh El Nino sangat kuat yang terjadi pada tahun 2015 (Tabel 3). Menurut Gaol dan Sadhotomo (2007), pada saat ENSO wilayah Indonesia memiliki curah hujan yang sangat rendah dan intensitas matahari menjadi lebih tinggi. Tingginya intensitas penyinaran matahari menjadikan faktor penyebab melimpahnya konsentrasi klorofil-a pada saat terjadinya ENSO. Meningkatnya kadar nutrien maka akan meningkatkan produktivitas primer yang menghasilkan konsentrasi klorofil-a yang tinggi pula (Kunarso, et al., 2011).

\section{Hasil Tangkapan Skipjack Tuna}

Berdasarkan hasil plot data menunjukkan bahwa hasil tangkapan ikan skipjack tuna periode Desember 2010 hingga November 2015 memiliki jumlah yang berbeda pada setiap musim. Grafik pada gambar 4.4 menyatakan bahwa Catch Per Unit Effort (CPUE) sangat mempengaruhi hasil tangkapan skipjack tuna, ketika effort (upaya penangkapan) meningkat, maka hasil tangkapan juga ikut meningkat, begitupun sebaliknya, CPUE yang menurun mengakibatkan penurunan hasil tangkapan ikan skipjack tuna.

Jumlah penangkapan ikan skipjack tuna dominan periode tahun 2011 sebesar 227.479 metric ton pada saat musim peralihan II dengan CPUE 608.23 metric ton/days, sedangkan tahun 2012 jumlah tangkapan skipjack tuna dominan pada saat musim peralihan I yaitu 210.602 metric ton dengan CPUE sebesar 1.164 metric ton/days. Untuk tahun 2013 hasil tangkapan ikan skipjack tuna paling banyak adalah sebesar 268.100 metric ton ketika musim timur dengan CPUE 570,16 metric ton/days. Pada tahun 2014 jumlah tangkapan terbanyak saat musim peralihan I, yakni sebesar 237.258 metric ton dengan CPUE 739,14 metric ton/days. Sedangkan untuk tahun 2015 hasil tangkapan skipjack tuna dominan terjadi pada saat musim peralihan II, yaitu sebesar 388.745 metric ton dengan CPUE 1.102 metric ton/days.

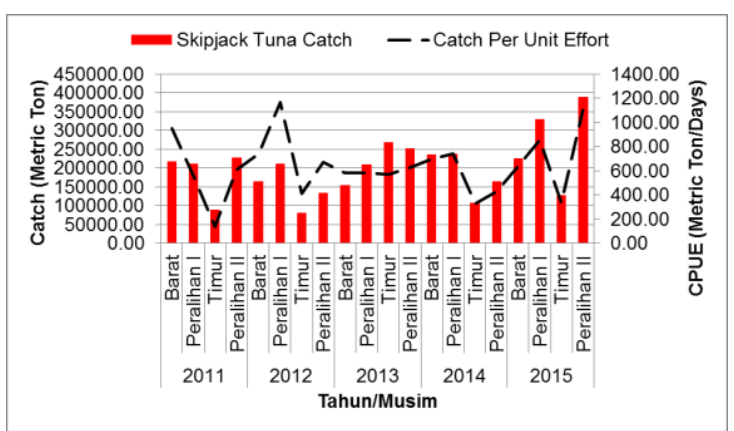

Gambar 5. Grafik Hasil Tangkapan Skipjack Tuna Tiap Musim

\section{Hubungan Klorofil-a dengan Skipjack Tuna}

Salah satu parameter yang sangat berpengaruh terhadap keberadaan ikan di suatu perairan adalah ada tidaknya sumber makanan yang dibutuhkan. Sumber makanan ikan terkonsentrasi di wilayah perairan yang subur. Daerah perairan yang subur memiliki kandungan nutrien yang tinggi, seperti orthoposphat, nitrat, nitrit dan unsur hara lainnya. Daerah ini biasanya diindikasikan dengan kelimpahan fitoplankton yang tinggi 
dan konsentrasi klorofil-a yang tinggi pula (Supangat et al., 2004; Pranowo et al., 2005; Abigail dkk., 2015; Utamy et al., 2015). Pola distribusi skipjack tuna berkorelasi nyata dengan distribusi zooplankton dan mikronekton. Meningkatnya kelimpahan skipjack tuna di sekitar pulau, gunung dan lembah laut disebabkan oleh besarnya ketersediaan makanan di daerah tersebut sehingga ikan-ikan skipjack tuna tersebut akan berpindah ke daerah lain dengan melakukan migrasi untuk mencari daerah baru yang kaya akan bahan makanan (Amiruddin, 1993; Setyadji et al., 2018; Tussadiah et al., 2018).

Gambar 6 menunjukkan bahwa pada tahun 2011 terjadi penurunan tajam nilai CPUE dari Musim Barat ke Musim Timur hingga mencapai 140,84 metric ton/days dengan hasil tangkapan 88.781 metric ton, namun berbanding terbalik dengan nilai konsentrasi klorofil-a yang justru mengalami peningkatan sebesar $0,1968 \mathrm{mg} / \mathrm{m}^{3}$. Tahun 2012 hal yang sama terjadi pada musim peralihan I menuju ke musim timur, CPUE skipjack tuna mengalami penurunan tajam hingga 408,11 metric ton/days dan diikuti penurunan hasil tangkapan sebesar 80.780 metric ton namun nilai rata-rata konsentrasi klorofil-a meningkat sebesar 0,1694 mg/m³.

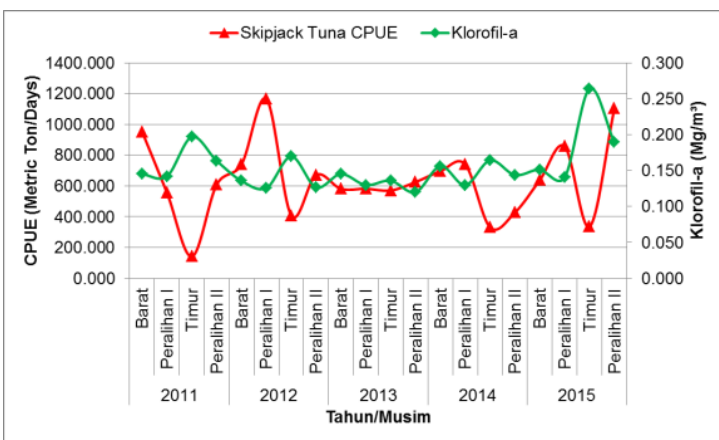

Gambar 6. Grafik Fluktuasi Hubungan

Konsentrasi Klorofil-a dengan Skipjack Tuna CPUE

Pada tahun 2013 fenomena kenaikan hasil tangkapan ikan terjadi pada Musim Timur sebesar 268.100 metric ton dengan CPUE sebesar 570,16 metric ton/days, namun dengan nilai konsentrasi klorofil-a yang relatif stabil pada setiap musimnya. Tahun 2014 peningkatan konsentrasi klorofil-a terjadi pada Musim Timur namun terjadi penurunan tajam pada hasil tangkapan skipjack tuna yakni sebesar 105.693 metric ton dengan nilai CPUE 330,32 metric ton/days. Hal sama terjadi pada tahun 2015 dimana terjadi kenaikan konsentrasi klorofil-a pada Musim Timur dengan nilai sebesar $0,2638 \mathrm{mg} / \mathrm{m}^{3}$ namun terjadi penurunan tajam hasil tangkapan, yaitu 127.400 metric ton dan diikuti penurunan CPUE hingga 334,98 metric ton/days.

Hasil analisis lebih detail secara statistik menggunakan metode time shifting correlation untuk membuktikan respon ikan skipjack tuna terhadap konsentrasi klorofil-a (bulanan) dapat dilihat pada gambar 7 . Diketahui skipjack tuna memiliki tingkat keeratan hubungan terhadap klorofil-a dengan koefisien korelasi sebesar $(-0,31)$, selain itu skipjack tuna mempunyai beda fase terhadap klorofil-a yang ditunjukkan pada puncak koefisien tertinggi berada pada nilai 1. Hal tersebut dapat diindikasikan skipjack tuna tidak merespon secara langsung terhadap kelimpahan klorofil-a namun membutuhkan interval waktu (time lag), skipjack tuna mencapai nilai CPUE maksimum setelah satu bulan pencapaian jumlah maksimum klorofil-a.

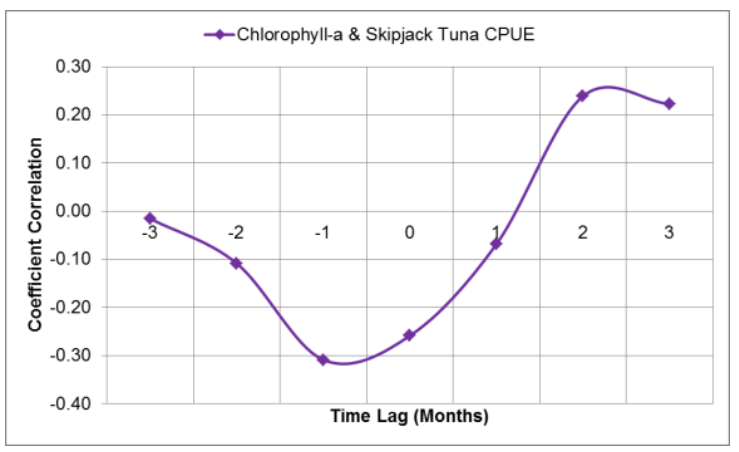

Gambar 7. Time Shifting Correlation

Konsentrasi Klorofil-a dengan Skipjack Tuna CPUE

Diketahui klorofil-a bukan makanan utama ikan skipjack tuna, makanan utama skipjack tuna adalah ikan-ikan kecil, crustaceae dan mollusca (FAO, 1983). Hal ini terkait dengan proses terjadinya rantai makanan yang bergerak secara linear dari produsen hingga konsumen teratas. Nybakken (1992) menyebutkan fitoplankton merupakan produsen utama dalam sistem mata rantai di laut, tumbuhan laut ini bebas melayang dan hanyut dalam laut serta mampu melakukan fotosintesis, oleh karena itu tanpa adanya tumbuhan berukuran renik ini tidak mungkin adanya kehidupan di laut. Klorofil-a berkaitan erat dengan produktifitas primer yang ditunjukkan dengan besarnya biomassa fitoplankton yang menjadi rantai pertama makanan ikan pelagis kecil.

Fitoplankton sebagai tumbuhan yang mengandung pigmen klorofil mampu melaksanakan reaksi fotosintesis, dimana air dan karbondioksida dengan adanya sinar matahari dan garam-garam hara terlarut dapat menghasilkan senyawa organik seperti karbohidrat. Karena kemampuan untuk menghasilkan zat organik dari zat anorganik ini maka fitoplankton disebut sebagai 
produsen primer (Nontji, 2005). Pigmen yang umum didapat adalah klorofil a, b dan $\mathrm{c}$. Namun yang paling dominan adalah klorofil-a. Salah satu fungsi klorofil adalah untuk menyerap energi elektromagnetik (cahaya) yang datang untuk digunakan dalam proses fotosintesis (Gaol, 2003). Fitoplankton menjadi dasar dari rantai makanan yang dimakan oleh zooplankton, kemudian zooplankton akan dimangsa oleh ikan-ikan kecil serta secara berkelanjutan ikan-ikan kecil akan dimangsa oleh ikan predator lain yang lebih besar termasuk skipjack tuna.

\section{Identifikasi Jadwal Patroli Keamanan Laut \\ Patroli keamanan laut dalam} penelitian ini difokuskan pada kegiatan yang memanfaatkan data citra satelit level 3 untuk menganalisis parameter sebaran klorofil-a di perairan Laut Maluku dari tindak pidana IUUFishing. Hasil pengamatan parameter konsentrasi klorofil-a dan data perikanan tangkap skipjack tuna yang terjadi selama tahun 2011 hingga tahun 2015 dapat dimanfaatkan sebagai dasar perencanaan untuk menentukan waktu terbaik dalam melaksanakan operasi keamanan laut, dengan didukung data yang akurat secara spasial, maka kegiatan operasi akan lebih efektif dan efisien.

Pada tahun 2011 sebaran klorofil-a dengan konsentrasi tinggi terjadi pada bulan Januari, Februari, Juni, Juli, Agustus, September serta November. Tahun 2012 konsentrasi klorofil-a tinggi terjadi pada bulan Juli dan Agustus, untuk tahun 2013 klorofil-a tinggi terjadi hanya pada bulan Januari. Sebaran klorofil-a dengan konsentrasi tinggi pada tahun 2014 terjadi di Bulan Januari, Februari, Juli, Agustus dan September, sedangkan tahun 2015 konsentrasi klorofil-a tinggi terjadi pada Bulan Januari, Februari, Maret, Juni, Juli, Agustus, September, Oktober serta November. Konsentrasi klorofil-a yang tinggi tidak selalu diikuti dengan kelimpahan hasil tangkapan skipjack tuna di setiap bulannya, keadaan ini dapat dipengaruhi oleh faktor lain, misalnya kemampuan nelayan, jenis dan teknologi alat tangkap serta keadaan cuaca ketika melaut.

Berdasarkan analisis data yang telah dilakukan, diperoleh hasil yang menyatakan bahwa potensi terjadinya tindak pidana IUUFishing dapat ditentukan berdasarkan sebaran klorofil-a dengan nilai konsentrasi rata-rata minimum $0,2 \mathrm{mg} / \mathrm{m}^{3}$ serta mempertimbangkan jeda waktu (time lag) pada saat blooming fitoplankton hingga melimpahnya perikanan di area penelitian.
Tabel 4. Estimasi Jadwal Patroli Terbaik

\begin{tabular}{|c|c|c|c|c|c|c|}
\hline \multirow{3}{*}{ Tahun } & \multicolumn{6}{|c|}{ Musim } \\
\hline & \multicolumn{3}{|c|}{ Barat } & \multicolumn{3}{|c|}{ Peralihan I } \\
\hline & Des & Jan & Feb & Mar & Apr & Mei \\
\hline 2011 & & & $\mp$ & $\ddagger$ & & \\
\hline 2012 & $\ddagger$ & & & & & \\
\hline 2013 & & & $\ddagger$ & & & \\
\hline 2014 & & & $\mp$ & $\ddagger$ & & \\
\hline 2015 & & & $\mp$ & $\mp$ & $\ddagger$ & \\
\hline \multirow{3}{*}{ Tahun } & \multicolumn{6}{|c|}{ Musim } \\
\hline & \multicolumn{3}{|c|}{ Timur } & \multicolumn{3}{|c|}{ Peralihan II } \\
\hline & Jun & Jul & Agt & Sep & Okt & Nov \\
\hline 2011 & & $\mp$ & $\mp$ & $\ddagger$ & $\ddagger$ & \\
\hline 2012 & & & $\mp$ & $\ddagger$ & & \\
\hline 2013 & & & & & & \\
\hline 2014 & & & $\mp$ & $\mp$ & $\ddagger$ & \\
\hline 2015 & & $\ddagger$ & $\mp$ & $\ddagger$ & $\ddagger$ & $\mp$ \\
\hline
\end{tabular}

\section{KESIMPULAN DAN SARAN}

\section{Kesimpulan}

1. Dari hasil pengolahan dan analisis data sebaran klorofil-a di Perairan Laut Maluku, maka dapat diketahui bahwa rata-rata konsentrasi klorofil-a di Perairan Laut Maluku periode Desember 2010 - November 2015 adalah $0,1126-0,3260 \mathrm{mg} / \mathrm{m}^{3}$. Hasil pengolahan data menunjukkan konsentrasi klorofil-a lebih tinggi pada perairan pantai dan pesisir, sedangkan nilai konsentrasi rendah berada di daerah lepas pantai. Area tertentu di perairan lepas pantai yang memiliki konsentrasi klorofil-a dalam jumlah cukup tinggi disebabkan oleh tingginya konsentrasi nutrien yang dihasilkan melalui proses fisik massa air. Kemudian, konsentrasi klorofil-a tinggi dominan terjadi pada tahun 2015 yang diduga disebabkan oleh El Nino sangat kuat, secara spasial terlihat kenaikan nilai rata-rata konsentrasi sebesar 0,18 hingga $0,33 \mathrm{mg} / \mathrm{m}^{3}$ pada musim timur, yakni antara bulan Juni, Juli dan Agustus.

2. Hubungan hasil tangkapan skipjack tuna memiliki tingkat keeratan terhadap sebaran klorofil-a dengan koefisien korelasi sebesar (0,31 ) dan mempunyai beda fase yang ditunjukkan pada puncak koefisien tertinggi berada pada nilai 1. Sehingga dapat diindikasikan skipjack tuna tidak merespon secara langsung terhadap kelimpahan klorofila namun membutuhkan interval waktu (time lag) selama satu bulan.

3. Hasil kajian dalam penelitian ini menunjukkan bahwa pada saat Musim Barat Bulan Januari merupakan waktu untuk melakukan persiapan, sedangkan waktu terbaik untuk melaksanakan patroli adalah Bulan Februari dan Maret. Kemudian pada saat Musim Timur Bulan Juli merupakan waktu persiapan patroli, sedangkan waktu terbaik untuk melaksanakan patroli keamanan laut adalah Bulan Agustus dan September. 


\section{Saran}

Dengan adanya informasi spasial dan temporal pola sebaran klorofil-a, disarankan kepada TNI AL untuk memantau kelimpahan klorofil-a secara kontinyu, sehingga kegiatan operasi keamanan laut terhadap tindak pidana IUU-Fishing dapat dilaksanakan secara efektif dan efisien, mulai dari tahap perencanaan, dukungan logistik yang disesuaikan dengan kekuatan pangkalan, serta waktu terbaik dalam melaksanakan patroli.

\section{Persantunan}

Kontribusi Dhedy A. Maydwika, Widodo S. Pranowo dan Gentio Harsono pada artikel ini adalah sama. Persiapan dan validasi data dilakukan di Laboratorium Data Laut dan Pesisir, Pusat Riset Kelautan, KKP. Sedangkan proses analisis dilakukan di Laboratorium Hidro-Oseanografi, STTAL, Kluster Riset Bina Samudera, Ancol, Jakarta Utara. Data klorofil-a diunduh dari website NASA Ocean Color dan data perikanan tangkap skipjack tuna dari WCPFC (Western and Central Pacific Fisheries Commission). Analisis spasial menggunakan software Ocean Data View yang dibangun oleh Prof. Dr. Reiner Schlitzer dari Alfred Wegener Institute for Polar and Marine Research, Bremerhaven, Jerman.

\section{DAFTAR PUSTAKA}

Abigail, W., M. Zainuri, A.T.D. Kuswardani, W.S. Pranowo. 2015. Sebaran nutrien, intensitas cahaya, klorofil-a dan kualitas air di Selat Badung pada Monsun Timur. J. Depik 4(2): 87-94.

Adnan, 2010. Analisis Suhu Permukaan laut dan Klorofil-a Data Inderaja Hubungannya dengan Hasil Tangkapan Ikan Tongkol (Euthynnus affinis) Di Perairan Kalimantan Timur. Jurnal Amanisal PSP FPIK Unpatti Ambon 1(1): 1 - 12.

Amiruddin, 1993. Analisis Penangkapan Cakalang dengan Pole and Line di Perairan Teluk Bone dalam Hubungannya dengan Kondisi Oseanografi Fisika. Fakultas Perikanan Institut Pertanian Bogor. Bogor.

Chatfield, C., 2017. The Analysis of Time Series : an Introduction. CRC Press, Florida.

Edy, I., 2009. Pengenalan Operasi Kamla, Diktat Pelajaran Diklapa KODIKLATAL. Surabaya.
Fausan. 2011. Pemetaan Daerah Potensial Penangkapan Ikan Cakalang (Katsuwonus Pelamis) Berbasis Sistem Informasi Geografis di perairan Teluk Tomini Provinsi Gorontalo. Skripsi Jurusan Perikanan Universitas Hasanuddin. Makassar.

Food and Agriculture Organization of the United Nations. "FAO Species Catalogue Vol.2 Scombrids of the World". 1983. http://www.fao.org/3/ac478e/ac478e07. pdf.

Gaol, J.L., 2003. Kajian Karakter Oseanografi Samudera Hindia bagian timur dengan menggunakan multisensor citra satelit dan hubungannya dengan hasil tangkapan Tuna mata besar (Thunnus obesus). Disertasi, Program Pasca Sarjana, IPB, Bogor.

Gaol, J. L dan B. Sadhotomo. 2007. Karakteristik dan Variabilitas Parameter Oseanografi Laut Jawa Hubungannya dengan Distribusi Hasil Tangkapan Ikan. Jurnal Penelitian Perikanan Indonesia 13(3): 1-12.

Gower, J.F.R. \& J.R. Apel (eds.), 1972. Opportunities and Problems in Satellite Measurements of the Sea, UNESCO Tech. Pap. 46. 70 p.

Harsono, G. (2016). Metodologi Penelitian, Semester I S1/XXXIX-2019, Modul Pelajaran. Prodi Hidrografi, Sekolah Tinggi Teknologi Angkatan Laut (STTAL). Jakarta.

Kunarso, D. H., 2011. Kajian Kesuburan Ekosistem Perairan Laut Sulawesi Tenggara berdasarkan Aspek Bakteriologi, Jurnal IImu dan Teknologi Kelautan Tropis 3(2): 32-47.

Naim, A., 2010. Pengawasan Sumberdaya Perikanan Dalam Penanganan Illegal Fishing di Perairan Provinsi Maluku Utara. J. Agribisnis Perikanan 3(2): 14.

Nikyuluw, LLU. 2005, Kajian Variasi Musiman Suhu Permukaan Laut dan Klorofil dalam Hubungannya Dengan Penangkapan Lemuru di Perairan Selatan Bali. Disertasi, Program Pasca Sarjana, IPB, Bogor. 
Nontji, A., 2005. Laut Nusantara, Penerbit Sjambatan, Jakarta. 372.

Nybakken, J.W., 1992, Biologi Laut Suatu Pendekatan Ekologis, PT. Gramedia Jakarta, 459 hal.

Pranowo, W.S. (2016a). Hitung Perataan, Semester I S1/XXXIX-2019, Modul Pelajaran. Prodi Hidrografi, Sekolah Tinggi Teknologi Angkatan Laut (STTAL). Jakarta.

Pranowo, W.S., N.S. Ningsih, A. Supangat. 2005. Modelling of Nitrogen Compound Distribution in Jepara Waters, Northern Coast of Central Java - Indonesia. Journal of JTM 12(2): 116-123.

Ramansyah, F., 2009. Penentuan Pola sebaran konsentrasi klorofil-a di selat sunda dan perairan sekitar dengan menggunakan data inderaan Aqua Modis. Skripsi. PS ITK FPIK IPB. Bogor.

Rasyid J., Abd, \& Ibrahim. 2013. Spermonde Kondisi Oseanografi Versus Ikan Pelagis. Makassar: Masagena Press.

Sarwono, J., 2006. Metode Penelitian Kuantitatif dan Kualitatif. Graha IImu, Yogyakarta.

Setyadji, B., W.S. Pranowo, K. Amri. 2018. Sea-Air Impacts on Fishing Season of Hand Line Skipjack Tuna Katsuwonus pelamis (Linnaeus, 1758) in Pacitan Coastal Waters of The South Eastern Indian Ocean. J. Omni-Akuatika 14(1): 1-10.

Supangat A., T.R. Adi, W.S. Pranowo, \& N.S. Ningsih. 2004. Predicting Movement of The Warm Pool, The Salinity Front, and The Convergence Zone in The Western and Central Part of Equatorial Pacific Using a Coupled HydrodynamicalEcological Model. Proceeding The Twelfth OMISAR Workshop on Ocean Models (WOM-12), 7-10 September, 2004. Dalian, P.R. china. page: 11-1 11-11.

Syetiawan, A., 2015. Penentuan Zona Potensi Penangkapan Ikan Berdasarkan Pola Sebaran Klorofil-a. Jurnal IImiah Geomatika 21(2): 131 - 136.
Tussadiah, A., W.S. Pranowo, M.L. Syamsuddin, I. Riyantini, B. Nugraha, D. Novianto. 2018. Characteristic of eddies kinetic energy associated with yellowfin tuna in southern Java Indian Ocean. IOP Conf. Ser.: Earth Environ. Sci. 176 (1): 012004.

Utamy, R.M., N.P. Purba, W.S. Pranowo, \& H. Suherman. 2015. The Pattern of South Equatorial Current and Primary Productivity in South Java Seas. International Proceedings of Chemical, Biological and Environmental Engineering 90(24): 152-156.

Valiela, I., 1984. Marine Ecological Processes. Library of Congress Catalogy in Publication Data, New York, USA.

https://oceancolor.gsfc.nasa.gov//3/ (diakses 19 September 2019).

https://www.ggweather.com (diakses 23 September 2019).

https://www.wcpfc.int/wcpfc-public-domainaggregated-catcheffort-datadownload-page (diakses 14 Agustus 2019). 